\title{
CARACTERIZAÇÃO REOLÓGICA DAS DIFERENTES FASES DE EXTRATO DE INULINA DE RAÍZES DE CHICÓRIA, OBTIDAS POR ABAIXAMENTO DE TEMPERATURA ${ }^{1}$
}

\author{
JULIANA T. C. LEITE ${ }^{2}$, KIL J. PARK ${ }^{3}$, JO ÃO R. P. RAMALHO ${ }^{4}$, DAVI M. FURLAN ${ }^{5}$
}

\begin{abstract}
RESUMO: A inulina é um ingrediente funcional, geralmente empregado na indústria alimentícia como substituto do açúcar ou da gordura. Esse ingrediente pode ser encontrado em diversos produtos vegetais, incluindo as raízes de chicória. Por ser um produto com solubilidade variável com a temperatura, a inulina sofre uma separação de fases ao ser resfriada, originando uma fase precipitada, mais viscosa, e uma fase sobrenadante, de menor viscosidade. O estudo das propriedades reológicas das diferentes fases do extrato de inulina é importante para o projeto de equipamentos, como misturadores e bombas. Neste trabalho, foi estudado o comportamento reológico, para três condições distintas de temperatura $\left(25 ; 40\right.$ e $\left.50{ }^{\circ} \mathrm{C}\right)$, das fases sobrenadante e precipitada do extrato líquido de inulina, extraído de raízes de chicória por difusão em água quente e resfriado a duas temperaturas distintas $\left(8\right.$ e $\left.-10^{\circ} \mathrm{C}\right)$, sofrendo separação de fases. A fase precipitada foi analisada em duas condições: pura e com a adição de agentes microencapsulantes. Todos apresentaram um comportamento linear, semelhante ao dos "Plásticos de Bingham", porém, nem todos se ajustaram a esse modelo.
\end{abstract}

PALAVRAS-CHAVE: viscosidade, resfriamento, ingrediente funcional.

\section{RHEOLOGICAL CHARACTERIZATION FOR DIFFERENT PHASES OF INULIN EXTRACT FROM CHICORY ROOTS, OBTAINED THROUGH TEMPERATURE REDUCTION}

SUMMARY: Inulin is a functional food ingredient, generally employed as sugar or fat substitute in food systems. This ingredient can be found in several vegetal products, including chicory roots. As the solubility of inulin is susceptible to temperature changes, the product suffers a fractionalization resulting in two phases when cooled, originating a precipitated phase, more viscose, and a liquid phase, of lesser viscosity. The study of rheological properties of different phases of inulin extract is important for equipment designing, such as mixer and bombs. In this work, rheological behavior at three different temperatures $\left(25 ; 40\right.$ and $\left.50{ }^{\circ} \mathrm{C}\right)$ was determined for liquid and precipitated phases of inulin liquid extract, extracted from chicory roots by hot water diffusion and cooled at two different temperatures $\left(8\right.$ and $-10{ }^{\circ} \mathrm{C}$ ), suffering phases separation. The precipitated phase was analyzed in two conditions: pure and with the addition of microencapsulating agents (maltodextrin and hydrolized starch). All of them presented a linear behavior, similar to that of the "Plastics of Bingham". Some of them, however, were not an adequate fit to this model.

KEYWORDS: viscosity, cooling, functional ingredient.

\footnotetext{
${ }^{1}$ Trabalho escrito para apresentação no XXX Congresso Brasileiro de Engenharia Agrícola - CONBEA 2001, Foz do Iguaçu - PR. Parte da dissertação de mestrado do primeiro autor apresentada à FEAGRI/UNICAMP. Financiamento: FAPESP, CNPq e FAEP.

2 Engenheira Agrícola, Doutoranda em Engenharia de Alimentos pela FEA/UNICAMP, DPPAG/FEAGRI/UNICAMP, Caixa Postal 6011, Campinas - SP, Fone/Fax: (0XX19) 3788.1076, e-mail: juliana@agr.unicamp.br

${ }^{3}$ Engenheiro de Alimentos, Professor Titular, DPPPAG/FEAGRI/UNICAMP, Campinas - SP.

${ }^{4}$ Graduando em Engenharia de Alimentos, FEA/UNICAMP.

${ }^{5}$ Graduando em Engenharia de Computação, FEEC/UNICAMP.

Recebido pelo Conselho Editorial em: 03-12-2001

Aprovado pelo Conselho Editorial em: 8-12-2003
} 


\section{INTRODUÇÃO}

A inulina é um polissacarídeo formado por uma cadeia de unidades de frutose com uma unidade de glicose terminal. De acordo com SILVA (1996), ela pode ser encontrada em mais de 30.000 espécies vegetais, dentre as quais, as raízes de chicória se destacam por apresentarem estabilidade na produção de cadeias longas de GFn e uma boa produtividade, mesmo em condições de clima moderado.

A inulina é um ingrediente altamente utilizado na indústria alimentícia em países da Europa, nos EUA e no Canadá, tendo sua principal aplicação relacionada com a sua capacidade de substituir o açúcar e a gordura sem fornecer grande quantidade de calorias, sendo, portanto, muito utilizado como ingrediente em produtos light, diet ou low fat.

Além da sua capacidade de substituir o açúcar e a gordura, a inulina também é um ingrediente funcional, atuando no organismo de maneira similar às fibras dietéticas.

De acordo com SILVA (1996), a inulina é solúvel em água, apresentando solubilidade dependente da temperatura. A $10{ }^{\circ} \mathrm{C}$, a solubilidade é de $6 \%$, ao passo que a $90{ }^{\circ} \mathrm{C}$, aumenta para aproximadamente $35 \%$.

BERGHOFER et al., citados por HÉBETTE et al. (1998), utilizaram a extração em água quente, seguida da concentração por evaporação e com cristalização subseqüente, por resfriamento, para isolar a inulina de raízes de chicória fatiadas. Quando a solução de inulina foi resfriada de 95 a $4{ }^{\circ} \mathrm{C}$ durante 30 horas, parte da inulina precipitou-se como uma substância pastosa, havendo uma separação de fases - sobrenadante (diluída) e precipitada (concentrada). Essa última fase poderia ser removida por filtração e, posteriormente, utilizada na produção de inulina em pó por spray dryer.

Para que a fase precipitada do extrato de inulina possa ser empregada na indústria alimentícia, é necessário conhecer o comportamento reológico da mesma.

O conhecimento do comportamento reológico de alimentos fluidos é essencial para o projeto de equipamentos de processamento de alimentos, além de ser um parâmetro de grande importância para controle de qualidade e aceitabilidade dos consumidores. O objetivo deste trabalho foi o de determinar o comportamento reológico, para três condições distintas de temperatura $\left(25 ; 40\right.$ e $\left.50{ }^{\circ} \mathrm{C}\right)$, das diferentes fases do extrato líquido de inulina, extraído de raízes de chicória por difusão em água quente e resfriado a duas temperaturas diferentes $\left(8 \mathrm{e}-10^{\circ} \mathrm{C}\right)$, sofrendo separação de fases. $\mathrm{O}$ comportamento reológico da fase precipitada também foi analisada com a adição de agentes microencapsulantes (maltodextrina e amido hidrolisado).

\section{MATERIAL E MÉTODOS}

\section{Obtenção do extrato}

O processo para a obtenção do extrato de inulina e posterior separação compreendeu as seguintes etapas:

- Extração: para a extração, adicionou-se água às raízes trituradas na proporção de 1:2 e levou-se essa mistura a um tacho encamisado a vapor, a $70^{\circ} \mathrm{C}$, durante 1 hora.

- Filtração: o extrato obtido foi filtrado para a retirada de pedaços ou partículas de raízes trituradas.

- Concentração: o extrato obtido foi levado a um evaporador encamisado a vapor até que se obtivesse uma concentração de aproximadamente $24{ }^{\circ}$ Brix. 
- Resfriamento/Congelamento: para a obtenção da separação de fases, o extrato líquido concentrado foi resfriado sob duas condições distintas de temperatura: a $8{ }^{\circ} \mathrm{C}$, correspondente à temperatura de um refrigerador, e a $-10{ }^{\circ} \mathrm{C}$, correspondente à temperatura de congeladores residenciais.

As amostras resfriadas à temperatura de $8{ }^{\circ} \mathrm{C}$ foram mantidas a essa temperatura durante 42 horas. Após esse período, as diferentes fases foram separadas e armazenadas em congelador para evitar sua deterioração. As amostras correspondentes à temperatura de $-10{ }^{\circ} \mathrm{C}$ foram congeladas e, para separação de fases, foram descongeladas e mantidas em refrigerador, também durante 42 horas, de forma a anular a interferência do fator tempo. Após esse período, as fases também foram separadas e armazenadas em congelador.

- Formulação com material de parede: A fase precipitada das amostras foi formulada com amido modificado (Dextrina 17) e com amido hidrolisado (Loremalt 2002), fornecidos pela Cia. Lorenz do Brasil.

A proporção de material de parede empregada foi de $15 \%$, dividido igualmente entre os dois tipos de amido, valor dentro da melhor faixa encontrada por NOGUEIRA (2001). A preparação das suspensões foi realizada por simples mistura.

\section{Caracterização reológica}

A caracterização reológica foi realizada nas temperaturas de $25 ; 40$ e $50{ }^{\circ} \mathrm{C}$ para as seguintes amostras:

- Fase sobrenadante, obtida às temperaturas de $8{ }^{\circ} \mathrm{C}(\mathrm{ST} 1) \mathrm{e}-10{ }^{\circ} \mathrm{C}(\mathrm{ST} 2)$;

- Fase precipitada, obtida às temperaturas de $8{ }^{\circ} \mathrm{C}(\mathrm{PT} 1)$ e $-10^{\circ} \mathrm{C}(\mathrm{PT} 2)$, e

- Fase precipitada, obtida às temperaturas de $8{ }^{\circ} \mathrm{C}(\mathrm{MPT} 1)$ e $-10^{\circ} \mathrm{C}(\mathrm{MPT} 2)$, formulada com material de parede a $15 \%$.

Para a determinação da viscosidade aparente da fase sobrenadante, utilizou-se do viscosímetro de cilindros concêntricos rotacionais Brookfield, modelo LVDV II, com sistema de sensor SC4-18, conectado a um sistema computadorizado de aquisição de dados (Wingather V.1.1 Brookfield Engineering Laboratories) para registrar a taxa de deformação, a viscosidade aparente e a tensão de cisalhamento. O viscosímetro utilizado está disponível na Faculdade de Engenharia de Alimentos (UNICAMP).

Foram utilizadas velocidades de rotação do spindle variáveis entre 105 e $200 \mathrm{rpm}$, o que correspondeu a taxas de deformação entre 139 e $264 \mathrm{~s}^{-1}$.

Para a determinação da viscosidade aparente da fase precipitada pura e formulada, utilizou-se do Reômetro Rotativo CV20N Haake Fisons, disponível no Departamento de Engenharia de Petróleo da Faculdade de Engenharia Mecânica (UNICAMP). Foi utilizado o escoamento entre placas paralelas, com o sensor PQ30 onde havia uma placa estacionária e outra rotativa. O espaçamento entre as placas (gap) utilizado foi de $1 \mathrm{~mm}$.

As taxas de deformação adotadas situaram-se entre 0,000 e $200.000 \mathrm{~s}^{-1}$.

As análises reológicas, para cada condição experimental, foram realizadas às temperaturas de 25 ; 40 e $50{ }^{\circ} \mathrm{C}$. Cada análise reológica foi executada duas vezes seguidas, sendo a primeira com taxa de deformação crescente e a segunda, decrescente. Os experimentos foram repetidos três vezes para que fosse possível escolher os melhores resultados. 


\section{Tratamento de dados}

A escolha do modelo reológico é feita com base nas características de escoamento do material em estudo. A descrição do comportamento reológico do material é feita por meio de modelos empíricos, que descrevem a relação entre tensão de cisalhamento e taxa de deformação.

Para fluidos ditos não-newtonianos, define-se a chamada viscosidade aparente $\left(\eta_{\mathrm{ap}}\right)$, a qual depende da taxa de deformação ou gradiente de velocidade $(\gamma)$ e da duração dessa taxa (fluidos nãonewtonianos dependentes do tempo).

Para alimentos que apresentam comportamento reológico independente do tempo, o modelo teórico de Herschel \& Bulkey [eq.(1)] pode ser aplicado para descrever a relação entre a tensão de cisalhamento e a taxa de deformação. Nesse modelo, é considerada a existência de uma tensão inicial $\left(\tau_{0}\right)$.

$$
\tau_{\mathrm{c}}=\mathrm{K} \gamma^{\mathrm{n}}+\tau_{0}
$$

em que,

$\tau_{0}$ - tensão inicial necessária para iniciar o escoamento do material;

$\mathrm{K}$ - índice de consistência, e

$\mathrm{n}$ - índice de comportamento ou índice reológico.

Os casos nos quais o índice reológico é igual a 1, são classificados como "Plásticos Bingham".

A eq.(1) foi utilizada para ajustar os dados experimentais obtidos de tensão de cisalhamento em função da taxa de deformação. O ajuste dos dados foi realizado de duas formas distintas: na primeira, desprezou-se a existência de uma histerese e a curva foi obtida de acordo com os valores médios. $\mathrm{Na}$ segunda, as curvas foram ajustadas separadamente, considerando-se uma equação para a deformação crescente e outra para a deformação decrescente.

Após o ajuste da eq.(1) aos dados experimentais, calculou-se o erro relativo entre dados experimentais e teóricos da tensão de cisalhamento, sendo os dados teóricos obtidos pela eq.(1), com base nos valores experimentais da taxa de deformação.

Os erros relativos foram calculados a partir da eq.(2), considerando as diferenças entre os valores teóricos, obtidos pela eq.(1) e os valores experimentais de tensão de cisalhamento.

$$
\mathrm{ER}=\frac{|\mathrm{VE}-\mathrm{VT}|}{\mathrm{VE}} 100
$$

em que,

ER - erro relativo;

VE - valor experimental, e

VT - valor teórico.

A partir dos valores obtidos para o erro relativo, calcularam-se os erros relativos médios para cada condição experimental.

\section{RESULTADOS E DISCUSSÃO}

\section{Curvas de tensão de cisalhamento em função da taxa de deformação}

As curvas de tensão de cisalhamento em função da taxa de deformação médias, obtidas para cada condição, mostram o comportamento reológico das amostras estudadas. 
Observou-se, para a maior parte das amostras, uma pequena histerese entre as curvas de taxa de deformação crescente (ida) e decrescente (volta). Nas curvas obtidas para a fase sobrenadante, a histerese mostrou-se menos acentuada.

Também foi possível notar que a viscosidade tende a diminuir com o aumento de temperatura. Essa diferença mostrou-se menos acentuada entre as temperaturas de 40 e $50{ }^{\circ} \mathrm{C}$, quando, em alguns casos, a viscosidade das amostras submetidas a $50{ }^{\circ} \mathrm{C}$ chegou a ser superior à viscosidade das amostras submetidas a $40{ }^{\circ} \mathrm{C}$.

Nas Figuras 1 e 2, estão apresentadas as curvas médias de tensão de cisalhamento em função da taxa de deformação, obtidas para a amostra da fase precipitada pura e para a amostra da fase sobrenadante, respectivamente. Ambas correspondem à temperatura de resfriamento de $8{ }^{\circ} \mathrm{C}$.

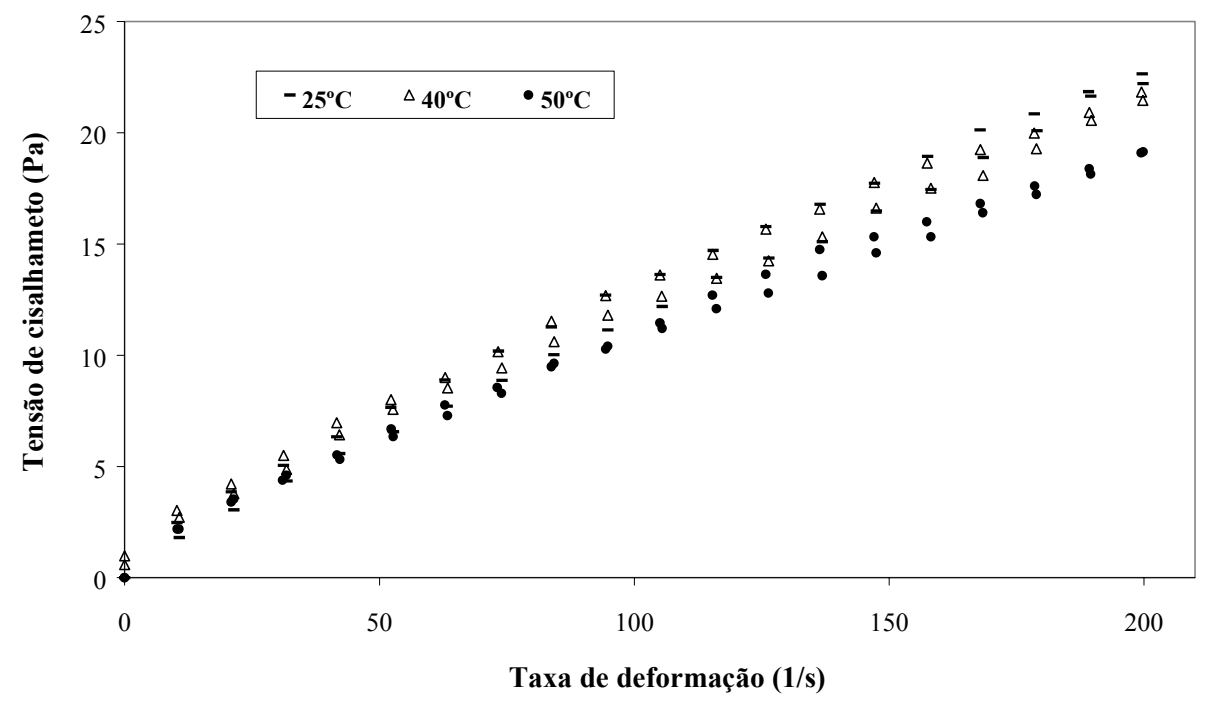

FIGURA 1. Curvas da tensão de cisalhamento em função da taxa de deformação para a amostra PT1, avaliadas às temperaturas de $25 ; 40$ e $50^{\circ} \mathrm{C}$.

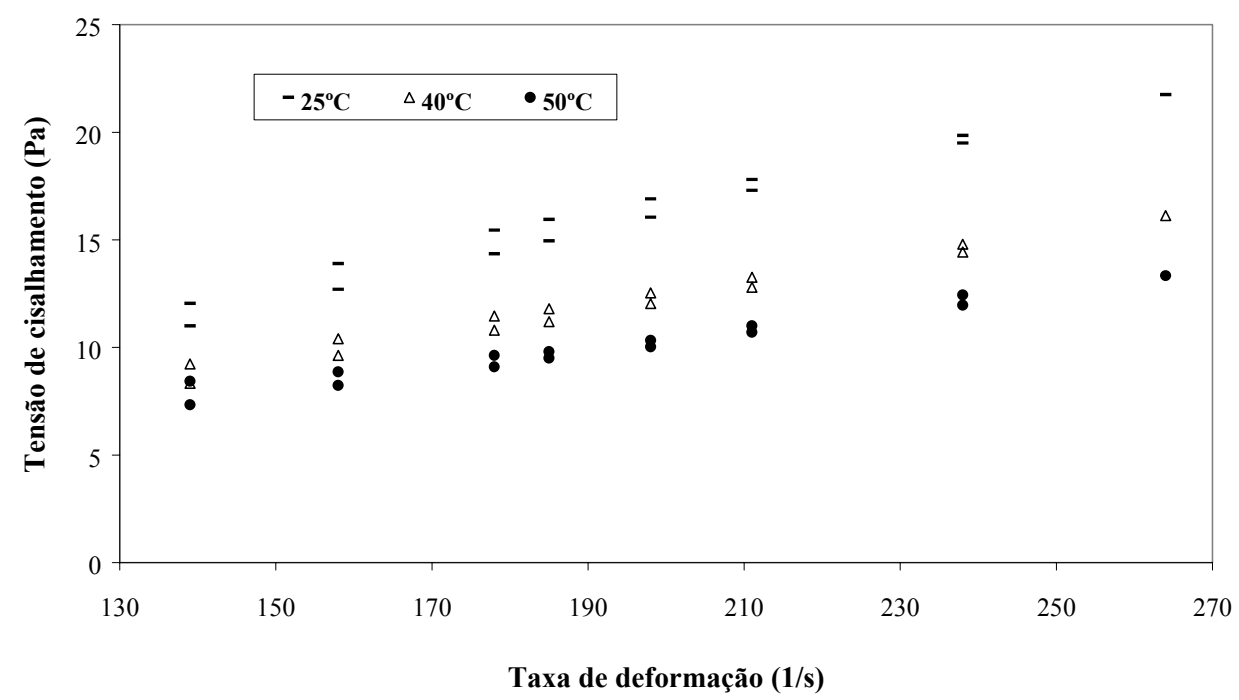

FIGURA 2. Curvas da tensão de cisalhamento em função da taxa de deformação para a amostra ST1, avaliadas às temperaturas de $25 ; 40$ e $50^{\circ} \mathrm{C}$. 
Para cada curva experimental obtida, traçou-se a linha de tendência correspondente, obtendo-se uma equação semelhante ao modelo Herschell-Bulkey com n=1 ("Plásticos de Bingham"), conforme apresentado na eq.(1).

$\mathrm{Na}$ Tabela 1, estão apresentados os valores obtidos para os parâmetros "K" e " $\tau_{\mathrm{o}}$ ", da eq.(1), bem como o coeficiente de determinação $\left(\mathrm{R}^{2}\right)$ correspondente ao ajuste adotado, para as duas formas de determinação (média e ida/volta).

$\mathrm{Na}$ Tabela 2, são apresentados os erros relativos médios correspondentes a cada equação de ajuste, para cada condição experimental.

Avaliando-se o erro relativo médio obtido para cada condição, percebe-se que as amostras armazenadas às temperaturas de $8 \mathrm{e}-10^{\circ} \mathrm{C}$ apresentaram bons ajustes, com erros relativos inferiores a $10 \%$, com exceção das amostras correspondentes à fase sobrenadante, obtidas a $-10{ }^{\circ} \mathrm{C}$ e avaliadas às temperaturas de 25 e $50{ }^{\circ} \mathrm{C}$.

Os valores encontrados para o erro experimental mostraram que as amostras apresentaram um comportamento compatível com o modelo utilizado para "Plásticos de Bingham".

TABELA 1. Parâmetros K e $\tau_{\mathrm{o}}$ da eq.(1), calculados para cada amostra.

\begin{tabular}{|c|c|c|c|c|c|c|c|c|c|c|c|}
\hline \multirow{3}{*}{$\begin{array}{c}\mathrm{T} \\
\text { resfr. }\end{array}$} & \multirow{3}{*}{\multicolumn{2}{|c|}{$\begin{array}{l}\text { Temperatura } \\
\text { Viscosidade }\end{array}$}} & \multicolumn{9}{|c|}{ Amostras } \\
\hline & & & \multicolumn{3}{|c|}{ Precipitado } & \multicolumn{3}{|c|}{ Material de Parede } & \multicolumn{3}{|c|}{ Sobrenadante } \\
\hline & & & $\mathrm{K}$ & $\tau_{\mathrm{o}}$ & $\mathrm{R}^{2}$ & $\mathrm{~K}$ & $\tau_{\mathrm{o}}$ & $\mathrm{R}^{2}$ & $\mathrm{~K}$ & $\tau_{\mathrm{o}}$ & $\mathrm{R}^{2}$ \\
\hline \multirow{9}{*}{$8^{\circ} \mathrm{C}$} & \multirow{3}{*}{$25^{\circ} \mathrm{C}$} & ida & 0,109 & 1,178 & 0,990 & 0,389 & 6,026 & 0,992 & $8 \mathrm{E}-05$ & $18 \mathrm{E}-04$ & 0,998 \\
\hline & & & 0,108 & 1,740 & 0,993 & 0,382 & 4,851 & 0,996 & -05 & 9E-04 & 1,000 \\
\hline & & & 0,109 & 0,694 & 0,998 & 0,387 & 5,336 & 0,992 & $8 \mathrm{E}-05$ & $4 \mathrm{E}-04$ & 0,976 \\
\hline & \multirow{3}{*}{$40{ }^{\circ} \mathrm{C}$} & ida & 0,100 & 2,498 & 0,991 & 0,294 & 7,303 & 0,996 & $5 \mathrm{E}-05$ & $24 \mathrm{E}-04$ & 0,999 \\
\hline & & volta & & 1,815 & 0,995 & 0,286 & 8,000 & 0,995 & $6 \mathrm{E}-05$ & $3 \mathrm{E}-04$ & 0,999 \\
\hline & & mé & 101 & 2,124 & 0,989 & 0,291 & 7,615 & 0,995 & 5E-05 & $14 \mathrm{E}$ & 0,970 \\
\hline & \multirow{3}{*}{$50{ }^{\circ} \mathrm{C}$} & ida & 0,091 & 1,560 & 0,992 & 0,239 & 3,530 & 0,997 & $4 \mathrm{E}-05$ & $24 \mathrm{E}-04$ & 0,987 \\
\hline & & & & 1,418 & 0,993 & 0,235 & 4,098 & 0,993 & $5 \mathrm{E}-05$ & & 1,000 \\
\hline & & & 0,091 & 1,471 & 0,992 & 0,238 & 3,801 & 0,995 & 4E-05 & $16 \mathrm{E}-04$ & 0,964 \\
\hline \multirow{9}{*}{$-10{ }^{\circ} \mathrm{C}$} & \multirow{3}{*}{$25^{\circ} \mathrm{C}$} & ida & & 4,840 & 0,971 & 0,349 & 4,9 & 0,994 & $3 \mathrm{E}-05$ & 10E-04 & 0,999 \\
\hline & & 11 & 0,147 & 1,812 & 0,998 & 0,341 & 4,562 & 0,996 & $4 \mathrm{E}-05$ & $2 \mathrm{E}-04$ & 0,995 \\
\hline & & & & & & 0,346 & 4,682 & 0,994 & $3 E-05$ & $6 \mathrm{E}-04$ & 0,991 \\
\hline & \multirow{3}{*}{$40{ }^{\circ} \mathrm{C}$} & $\mathrm{ida}$ & 0,117 & 2,988 & 0,972 & 0,271 & 3,520 & 0,995 & $2 \mathrm{E}-05$ & $2 \mathrm{E}-04$ & 0,999 \\
\hline & & volta & 0,117 & 1,496 & 0,996 & 0,262 & 4,276 & 0,993 & $2 \mathrm{E}-05$ & 4E-04 & 0,997 \\
\hline & & média & 0,118 & 2,182 & 0,976 & 0,267 & 3,860 & 0,994 & $2 \mathrm{E}-05$ & $3 \mathrm{E}-04$ & 0,994 \\
\hline & \multirow{3}{*}{$50{ }^{\circ} \mathrm{C}$} & ida & 0,091 & 1,624 & 0,990 & 0,258 & 4,095 & 0,996 & $1 \mathrm{E}-05$ & $14 \mathrm{E}-04$ & 0,984 \\
\hline & & volta & 0,088 & 1,868 & 0,987 & 0,252 & 6,013 & 0,988 & $1 \mathrm{E}-05$ & $12 \mathrm{E}-04$ & 0,987 \\
\hline & & média & 0,090 & 1,736 & 0,989 & 0,255 & 5,075 & 0,991 & $1 \mathrm{E}-05$ & $13 \mathrm{E}-04$ & 0,984 \\
\hline
\end{tabular}


TABELA 2. Erros relativos médios correspondentes a cada equação estimada.

\begin{tabular}{|c|c|c|c|c|c|}
\hline \multirow{2}{*}{$\begin{array}{l}\text { Temperatura } \\
\text { Resfriamento }\end{array}$} & \multirow{2}{*}{\multicolumn{2}{|c|}{ Temperatura Viscosidade }} & \multicolumn{3}{|c|}{ Amostra } \\
\hline & & & Precipitado & Material de Parede & Sobrenadante \\
\hline \multirow{9}{*}{$8{ }^{\circ} \mathrm{C}$} & \multirow{3}{*}{$25^{\circ} \mathrm{C}$} & média & $6,21 \%$ & $3,94 \%$ & $2,88 \%$ \\
\hline & & ida & $3,44 \%$ & $4,30 \%$ & $4,84 \%$ \\
\hline & & volta & $1,92 \%$ & $2,72 \%$ & $5,19 \%$ \\
\hline & \multirow{3}{*}{$40{ }^{\circ} \mathrm{C}$} & média & $4,47 \%$ & $2,68 \%$ & $6,29 \%$ \\
\hline & & ida & $4,18 \%$ & $2,40 \%$ & $0,50 \%$ \\
\hline & & volta & $2,95 \%$ & $2,71 \%$ & $3,19 \%$ \\
\hline & \multirow{3}{*}{$50{ }^{\circ} \mathrm{C}$} & média & $3,37 \%$ & $3,25 \%$ & $7,56 \%$ \\
\hline & & ida & $3,43 \%$ & $2,37 \%$ & $2,12 \%$ \\
\hline & & volta & $3,08 \%$ & $4,14 \%$ & $6,08 \%$ \\
\hline \multirow{9}{*}{$-10{ }^{\circ} \mathrm{C}$} & \multirow{3}{*}{$25^{\circ} \mathrm{C}$} & média & $11,13 \%$ & $3,77 \%$ & $11,04 \%$ \\
\hline & & ida & $7,88 \%$ & $4,30 \%$ & $6,53 \%$ \\
\hline & & volta & $1,64 \%$ & $2,78 \%$ & $11,30 \%$ \\
\hline & \multirow{3}{*}{$40{ }^{\circ} \mathrm{C}$} & média & $7,67 \%$ & $3,90 \%$ & $6,71 \%$ \\
\hline & & ida & $6,32 \%$ & $3,73 \%$ & $8,00 \%$ \\
\hline & & volta & $15,08 \%$ & $3,54 \%$ & $5,53 \%$ \\
\hline & \multirow{3}{*}{$50{ }^{\circ} \mathrm{C}$} & média & $4,43 \%$ & $4,15 \%$ & $20,59 \%$ \\
\hline & & ida & $4,48 \%$ & $2,36 \%$ & $18,67 \%$ \\
\hline & & volta & $4,13 \%$ & $4,33 \%$ & $17,41 \%$ \\
\hline
\end{tabular}

\section{Comparação das viscosidades}

Avaliando-se as Figuras 1 e 2, nas quais foram apresentadas as curvas da tensão de cisalhamento em função da taxa de deformação para as amostras precipitada e sobrenadante resfriadas à temperatura de $8{ }^{\circ} \mathrm{C}$ (PT1 e ST1, respectivamente), é possível perceber que a viscosidade aparente da fase precipitada do extrato de inulina é superior à da fase sobrenadante. Uma análise dos dados obtidos mostrou que a viscosidade aparente da fase precipitada foi da ordem de duas vezes superior à da fase sobrenadante correspondente, para as amostras resfriadas à temperatura de $8{ }^{\circ} \mathrm{C}$, e da ordem de 5 vezes superior para as amostras congeladas a $-10{ }^{\circ} \mathrm{C}$.

A adição de material de parede à fase precipitada também acarretou aumento na viscosidade aparente, como era esperado. As amostras formuladas apresentaram uma viscosidade aparente da ordem de 2 a 3 vezes superior à das amostras puras. Na Figura 3, encontra-se ilustrada essa situação para as amostras resfriadas à temperatura de $8{ }^{\circ} \mathrm{C}$ (PT1 e MPT1).

Comparando-se as amostras correspondentes à fase precipitada, obtidas a diferentes temperaturas de resfriamento do extrato puro, também foi possível perceber uma diferença na viscosidade aparente. Essa diferença mostrou-se mais acentuada à temperatura de $25^{\circ} \mathrm{C}$, quando a inulina apresenta menor solubilidade. Nessa condição, a viscosidade aparente da fase precipitada da amostra congelada a $-10^{\circ} \mathrm{C}$ (PT2) mostrou-se cerca de $1,5 \mathrm{vez}$ superior à da resfriada à temperatura de $8{ }^{\circ} \mathrm{C}(\mathrm{PT} 1)$. Para as temperaturas de 40 e $50{ }^{\circ} \mathrm{C}$, a viscosidade aparente foi semelhante para as duas condições de resfriamento, conforme ilustrado na Figura 4. 


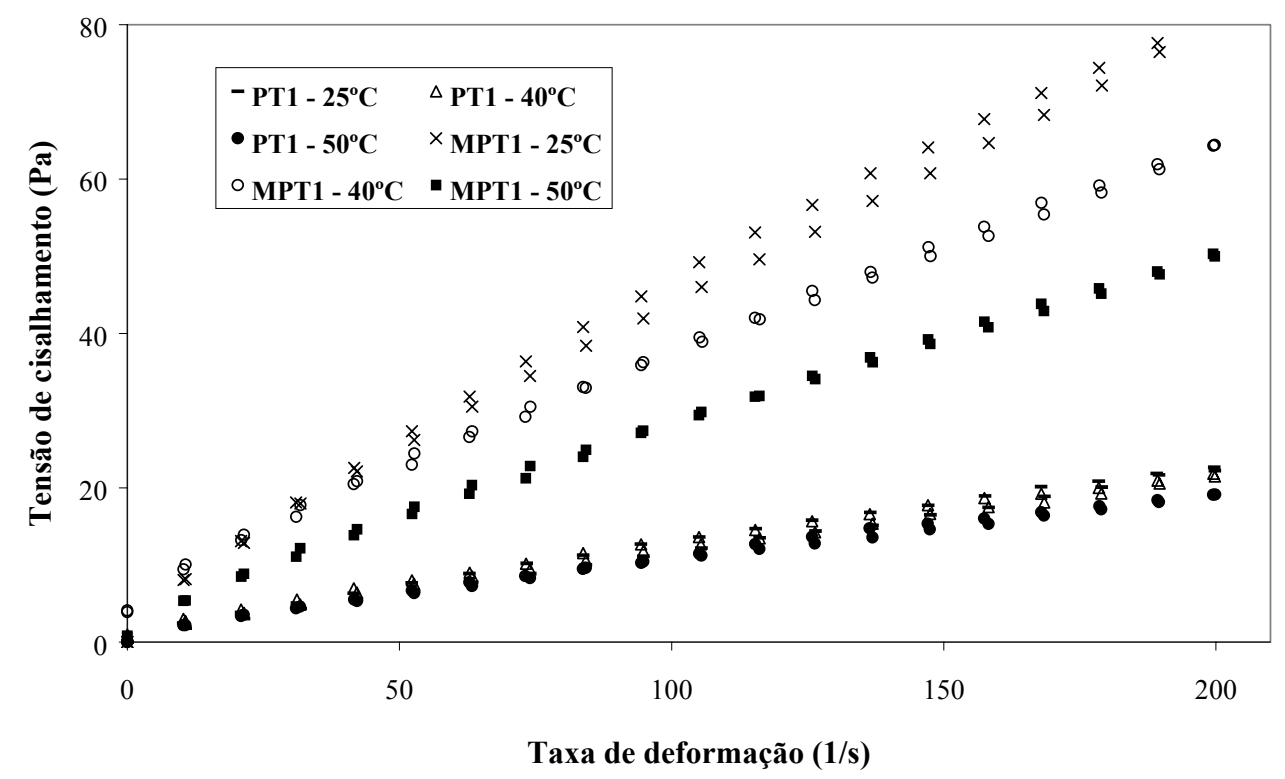

FIGURA 3. Curvas de tensão de cisalhamento em função da taxa de deformação para as amostras PT1 e MPT1, avaliadas às temperaturas de $25 ; 40$ e $50{ }^{\circ} \mathrm{C}$.

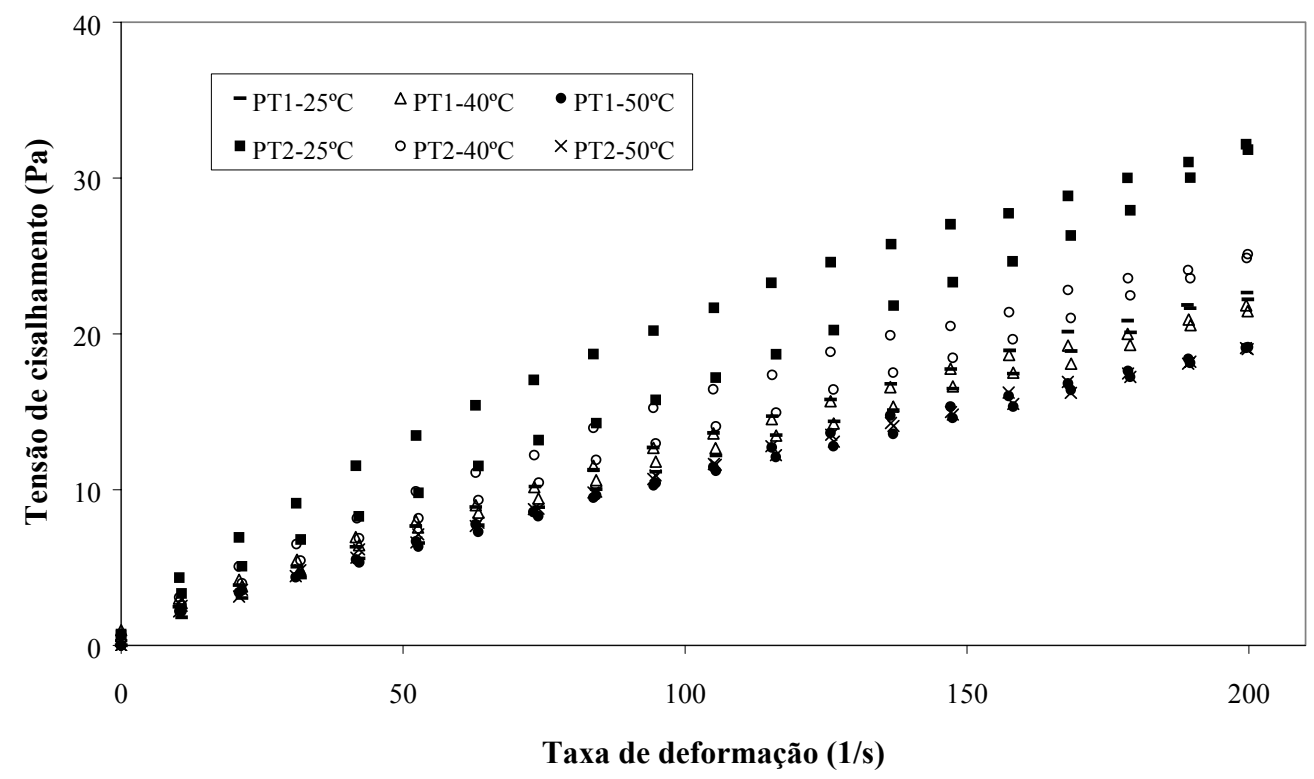

FIGURA 4. Curvas de tensão de cisalhamento em função da taxa de deformação para as amostras PT1 e MPT1, avaliadas às temperaturas de $25 ; 40$ e $50^{\circ} \mathrm{C}$.

As amostras correspondentes à fase sobrenadante também apresentaram uma diferença significativa nos valores da viscosidade aparente, de acordo com a temperatura de resfriamento. As amostras que foram resfriadas a $8{ }^{\circ} \mathrm{C}$ (ST1) se mostraram cerca de 2,5 vezes mais viscosas do que as que foram congeladas a $-10^{\circ} \mathrm{C}(\mathrm{ST} 2)$. 


\section{CONCLUSÕES}

Todas as curvas experimentais de tensão de cisalhamento, em função da taxa de deformação, foram bem ajustadas ao modelo de "Plásticos de Bingham", exceto as curvas da amostra ST2 obtidas a 25 e $50{ }^{\circ} \mathrm{C}$.

A fase precipitada mostrou-se de 2 a 5 vezes mais viscosa do que a sobrenadante, e a adição de material de parede provocou um aumento de 2 a 3 vezes na viscosidade aparente da fase precipitada.

Todas as amostras apresentaram viscosidade aparente dependente da temperatura, havendo uma tendência à redução da viscosidade aparente com o aumento da temperatura. Esse comportamento pode ser explicado pelo fato de que o aumento da temperatura provoca uma redução na solubilidade da inulina, causando uma redução na sua viscosidade.

A temperatura de resfriamento do extrato de inulina puro, para a obtenção das fases sobrenadante e precipitada, também exerceu influência sobre a viscosidade aparente das amostras. Para a fase precipitada, o congelamento das amostras resultou em aumento da ordem de 1,5 vez da viscosidade aparente. Para a fase sobrenadante, o resfriamento das amostras resultou em aumento na viscosidade aparente da ordem de 2,5 vezes. Dessa forma, é possível concluir que o resfriamento a temperaturas mais baixas reduz a solubilidade da inulina, tornando a fase sobrenadante mais diluída e a precipitada, mais concentrada.

A existência de uma histerese aparente nas curvas de tensão de cisalhamento em função da taxa de deformação pode significar a existência de um comportamento reológico dependente do tempo. Há, portanto, necessidade de realizar novos experimentos com a finalidade de verificar a existência de um comportamento tixotrópico das amostras.

\section{AGRADECIMENTOS}

À Fundação de Amparo à Pesquisa do Estado de São Paulo (FAPESP), ao Conselho Nacional de Desenvolvimento Científico e Tecnológico(CNPq), à Coordenação de Aperfeiçoamento de Pessoal de Nível Superior (CAPES) e à Faculdade de Engenharia Agrícola (FEAGRI/UNICAMP).

\section{REFERÊNCIAS BIBLIOGRÁFICAS}

BERGHOFER, E.; CRAMER, A.; SCHMIDT, V.; VEIGL, M. Pilot-scale production of inulin from chicory roots and its use in foodstuffs. In: FUCHS, A. (Ed.). Inulin and inulin containing crops. Amsterdam: Elsevier Science, 1993. p.77-84.

HÉBETTE, C.L.M.; DELCOUR, J.A.; KOCH, M.H.J. Complex melting of semi-crystalline chicory (Cichorium intybus L.) root inulin. Carbohydrate Research, Netherlands, v.310, n.1-2, p.65-75, 1998.

SILVA, R.F. Use of inulin as a natural texture modifier. Cereal Foods World, St. Paul, v.41, n.10, p.792-5, 1996.

NOGUEIRA, R.I. Processo de obtenção de inulina de chicória (Cichorium intybus) em pó. 2001. 120 f. Tese (Doutorado em Tecnologia da Pós-Colheita) - Faculdade de Engenharia Agrícola, Universidade Estadual de Campinas, Campinas, 2001. 